\title{
Effect of Cellulose Nanocrystals on the Performance of Oil-immersed Transformer Insulating Paper
}

\author{
Qijie Chen, ${ }^{\mathrm{a}, \mathrm{b}, *}$ Meicun Kang, ${ }^{\mathrm{a}}$ Zhi Rong, ${ }^{\mathrm{a}}$ and Zhangyang Zong ${ }^{\mathrm{a}}$
}

The possibility of enhancing both mechanical and breakdown properties of oil-immersed transformer insulating paper were considered by introduction of cellulose nanocrystals (CNCs). Two kinds of CNCs were taken into account: the TEMPO-oxidized CNCs (T-CNC) and the sulfuric acid hydrolyzed CNCs (S-CNC). Insulating paper containing no CNCs was also prepared as a reference. Obtained samples were characterized by Fourier transform infrared spectroscopy (FTIR), X-ray diffraction (XRD), and scanning electron microscopy (SEM). The effects of different amounts of CNC on tensile strength, AC breakdown strength, oil absorption rate, and conductivity of insulating paper extract were studied. The CNC improved the mechanical and electrical performances of insulating paper, and the effect of T-CNC was a little better than that of S-CNC. When the $\mathrm{T}$-CNC dosage was $0.9 \%$, the tensile strength, $\mathrm{AC}$ breakdown strength in oil, and oil absorption rate of the insulating paper were $70.22 \mathrm{~N} \cdot \mathrm{m} / \mathrm{g}, 59.8$ $\mathrm{kV} / \mathrm{mm}$, and $53.1 \%$, respectively, which was improved by $21.7 \%, 24.6 \%$, and $39.4 \%$, respectively, compared with the reference insulating paper. The beating degree of pulp also affected the mechanical and electrical properties of insulating paper containing CNC. Based on overall performance, it was concluded that CNCs are promising nano-additives for oil-immersed transformer insulating paper, especially for T-CNC.

Keywords: Transformer insulating paper; Cellulose nanocrystals; Breakdown strength; Tensile strength

Contact information: a: School of Chemistry and Food Engineering, Changsha University of Science and Technology, Changsha, Hunan Province, 410114, People's Republic of China; b: Key Laboratory of Pulp and Paper Science and Technology of Ministry of Education/Shandong Province, Qilu University of Technology (Shandong Academy of Sciences), Jinan, Shandong Province, 250353, People's Republic of China; *Corresponding author: chenqijie@126.com (Qijie Chen)

\section{INTRODUCTION}

Cellulose insulating paper, together with mineral oil, have been widely used in oilimmersed power transformers for many years due to their low cost and good insulating performances; the purpose of insulating paper impregnated with insulating oil is to resist the flow of electric current between the conductors (Lundgaard et al. 2004; Prevost and Oommen 2006). Although cellulose insulating paper has relative good properties, insulating breakdown is still the major factor that causes the electrical failures of oilimmersed power transformers (Oommen and Prevost 2006). With the development of ultra-high voltage power transmission, especially the $\pm 1100 \mathrm{kV}$ transmission system under construction in China, the reliability of oil-impregnated insulating paper has become a challenge that requires better insulation and mechanical properties of insulating paper (Ziomek 2012).

With the development of nanotechnology, new approaches may be considered for the modifications of insulating paper. The properties of melamine grafted nano- $\mathrm{SiO}_{2}$ modified insulating paper were studied, and the breakdown strength of the modified 
insulating paper has been improved (Tang et al. 2018). The electrical properties of insulating paper modified by nano-hollow $\mathrm{SiO}_{2}$ were investigated, and the $\mathrm{AC}$ breakdown field of the oil/nanomodified paper composite was increased from $26.4 \mathrm{kV}$ to $30.5 \mathrm{kV}$ (Liao et al. 2012). The addition of nano- $\mathrm{TiO}_{2}$ (Liao et al. 2013) or nano-montmorillonite (Yuan and Liao 2014) could improve the AC breakdown strength of the paper. Howerver, mechanical properties, which play a crucial role in determining the lifetime of insulating paper, normally decreased (Zhang et al. 2015; Tang et al. 2016). In addition, preparation process for the aforementioned nanomodified paper was usually complex due to the incompatibility between inorganic nanoparticles and organic cellulose fibers (Huang et al. 2017; Tang et al. 2017; Cao et al. 2019). Therefore, an organic nano-additive may be a good substitute, especially when it originates from cellulose fiber.

Cellulose nanocrystals (CNCs) are a polymer functional material and are extracted from fibers after a complete dissolution of the non-crystalline fraction (Habibi et al. 2010). The CNCs made from different methods and different raw materials have different properties. They have attracted much attention as reinforced nanofillers due to their good mechanical properties with high stiffness and elastic modulus (Campano et al. 2017; Herrera et al. 2017; Ding et al. 2018; Sheng et al. 2018). Compared to the inorganic nanoparticles, CNCs prepared from natural cellulose fiber are more compatible with cellulose insulation, and they have potential application in transformer insulating paper. Huang et al. (2017) explored different concentrations of nanofibrillated cellulose, cationic nanofibrillated cellulose, and anionic nanofibrillated cellulose as the potential nanoadditives on the mechanical and breakdown properties of insulating press paper. The results showed that the addition of nano-cellulose of $10 \mathrm{wt} \%$ can improve the tensile strength and insulation properties of insulating press paper.

In this study, Two types of CNC, prepared by TEMPO-oxidized (T-CNC) and sulfuric acid hydrolysis (S-CNC) respectively, were used as nano-additive in the insulating paper. The functional groups and crystallinities of the insulating paper were characterized by Fourier transform infrared spectroscopy (FTIR), X-ray diffraction (XRD), and scanning electron microscopy (SEM). To achieve a comprehensive understanding of the effect of CNCs, the performance including tensile strength, breakdown behavior, and oil absorption rate of insulating paper were measured and analyzed. Also, the effect of pulp properties on the properties of insulating paper containing CNC were investigated.

\section{EXPERIMENTAL}

\section{Raw Materials}

CNCs prepared by the TEMPO-oxidized (T-CNC) and by the sulfuric acid hydrolysis (S-CNC) were supplied by Tianjin University of Science and Technology (Tianjin, China). The carboxyl content of T-CNC was $0.8 \mathrm{mmol} / \mathrm{g}$. The unbleached $\mathrm{kraft}$ softwood pulp for the manufacture of insulating paper was supplied by Guangxin Paper Co. Ltd. (Hunan, China). The \#25 transformer oil was supplied by Kion Company (Hubei, China). Deionized water was used in all experiments.

\section{Preparation of Insulating Paper}

Preparation of reference insulating paper sample

The dry unbleached kraft softwood pulp was soaked in deionized water for $12 \mathrm{~h}$. The soaked pulp was refined by a PFI beater (KRK, Tokyo, Japan) to approximately 30 
Schopper-Riegler freeness ( $\left.{ }^{\circ} \mathrm{SR}\right)$. The $0.5 \mathrm{wt} \%$ pulp suspension was transferred to a RapidKöthern sheet former (Xi'an papermaking machine Co., Ltd, Xi'an, China) to make a handsheet with a basis weight of $80 \mathrm{~g} / \mathrm{m}^{2}$ according to the ISO 5269-2 (2004). Finally, the insulating paper were obtained after drying at $105^{\circ} \mathrm{C}$ for $15 \mathrm{~min}$.

\section{Preparation of insulating paper containing $C N C$}

The refined kraft pulp was re-dispersed with a pulper at a concentration of $0.5 \mathrm{wt} \%$. The suitable amount of CNC (T-CNC, S-CNC) suspension at $2.0 \mathrm{wt} \%$ was added to the pulp slurry. The suspension of fiber and $\mathrm{CNC}$ was then strongly stirred with a blender for $45 \mathrm{~s}$ to obtain a homogeneous suspension. After that, the subsequent sheet-forming and drying processes were the same as the preparation of the reference insulating paper sample.

\section{Transmission Electron Microscopy (TEM) Analysis}

The morphology of T-CNC and S-CNC were examined by Zeiss EM 109 TEM (Oberkochen, Germany). A drop of diluted CNCs aqueous suspension was deposited on a $\mathrm{Cu}$ microgrid (200 mesh) and allowed to dry. The grid was negatively stained with a 3\% $(\mathrm{w} / \mathrm{w})$ solution of uranyl acetate and dried at room temperature. The sample was observed at $80 \mathrm{kV}$. A hundred CNCs were randomly selected, and a minimum of 100 and 200 measurements were used to determine the average length and the diameter, respectively.

\section{FTIR Spectral Analysis}

FTIR spectra of the reference and the insulating paper containing different CNC were recorded by a Bruker Vertex 70v vacuum spectrometer (Karlsruhe, Germany) in reflection mode. FTIR samples were prepared by mixing the paper samples power with spectroscopic grade $\mathrm{KBr}$ (2 mg paper power / $200 \mathrm{mg} \mathrm{KBr}$ ) and compressed to the sheet. Each spectrum was recorded over the spectral range from $4000 \mathrm{~cm}^{-1}$ to $400 \mathrm{~cm}^{-1}$ with a spectral resolution of $2 \mathrm{~cm}^{-1}$ by 64 scans at room temperature. For each spectrum, the FTIR spectra were adjusted by subtraction of the $\mathrm{KBr}$ spectra (background)

\section{XRD Analysis}

The XRD patterns investigations of insulating paper containing different CNCs were measured on a D/MAX2200X X-ray diffractometer (Tokyo, Japan) with a Cuk $\alpha$ radiation source energized at $45 \mathrm{kV}$. Measurements were collected in the $2 \theta$ range from $10^{\circ}$ to $50^{\circ}$ at a rate of $1 \% \mathrm{~min}$. The measurement resolution was $0.02^{\circ}$. The peak height method was used to calculate the crystallinity index (CI) (Martins et al. 2011). The equation is:

$$
C I=\frac{I_{002}-I_{A M}}{I_{002}} \times 100 \%
$$

In this equation, $C I$ expresses the relative degree of crystallinity, $I_{002}$ was the intensity of the 002 crystalline peak, and $I_{\mathrm{AM}}$ was the intensity of the amorphous halo. All the measurements were carried out at least in duplicates. The software of MDI Jade and Origin were used to process the XRD curve.

\section{Tensile Strength}

Tensile strength was measured using an AUTOLINE 300 from Lorentzen and Wettre (Stock-holm, Sweden), following the ISO 1924-1 (2014). Separation speed of the 
two clamp was $100 \mathrm{~mm} / \mathrm{min}$, Size of the test strips was $150 \mathrm{~mm} \times 15 \mathrm{~mm}$. For each kind of insulating paper, eight measurements were conducted.

\section{Oil Absorption Rate}

The oil absorption rate of insulating paper was measured according to IEC 606412 (2004), and the size of test sample was $100 \mathrm{~mm} \times 100 \mathrm{~mm}$. The sample was first vacuum dried at $105{ }^{\circ} \mathrm{C}$ for $24 \mathrm{~h}$ to weigh the dry mass of the insulating paper $\left(M_{1}\right)$, and then a vacuum soaking \#25 transformer oil was carried out. After the vacuum removal, the sample was further soaked in oil for $6 \mathrm{~h}$. Finally, the excess transformer oil on the paper surface was wiped off and the weight of the oil-paper sample $\left(M_{2}\right)$ was weighed, and the oil absorption rate $(X)$ was calculated with the following equation,

$$
X=\frac{M_{1}-M_{2}}{M_{1}} \times 100 \%
$$

For each group of samples, three samples were measured, and the average value was taken as the oil absorption rate.

\section{AC Breakdown Strength}

AC breakdown voltage of insulating paper was measured using an HT-5/20A breakdown voltage tester produced by Guilin Electric Research Institute Co. Ltd. (Guilin, China) according to the IEC 60243-3 (2001). The electrode consists of two metal cylinders, where one edge is inverted into a circular arc with a radius of $3 \mathrm{~mm} \pm 0.2 \mathrm{~mm}$. One of the electrodes had a diameter of $25 \mathrm{~mm} \pm 1 \mathrm{~mm}$ and a height of $25 \mathrm{~mm}$, and the other one was $75 \pm 1 \mathrm{~mm}$ in diameter and $15 \mathrm{~mm}$ in height. The AC breakdown voltage in air was measured at room temperature in the air, and the AC breakdown voltage in oil was measured using the insulating oil as the dielectric surrounding the equipment. The size of the paper samples was $75 \mathrm{~mm} \times 75 \mathrm{~mm}$, which was large enough to prevent surface flashover. For each kind of insulation paper, eight measurements were taken.

\section{Conductivity of Insulating Paper Extract}

The insulating paper samples were cut $5 \mathrm{~mm} \times 5 \mathrm{~mm}$ in size, and extracted in a boiling deionized water bath for $60 \mathrm{~min}$. The conductivity of the extracted liquid was measured by a DDSJ-308A conductivity meter produced by Shanghai Electrical Science Instrument Co., Ltd (Shanghai, China) according to GB/T 7977 (2007).

\section{SEM Analysis}

The surface morphology of insulating paper were analyzed using a Jeol scanning electron microscope (JSM-6490LV, Kyoto, Japan).The images were obtained using an accelerating voltage of $20 \mathrm{kV}$.

\section{Statistical Analysis}

All the experiments were carried out at least three times. Mean values and standard deviations were analyzed and reported by using the Origin Program 8.0 (Origin Lab Company, USA). Statistical analysis was performed using EXCELTM 2016 (Microsoft, USA) and significant difference among the means was estimated at $95 \%$ confidence level $(\mathrm{P}<0.05)$. 


\section{RESULTS AND DISCUSSION}

\section{TEM Analysis of CNCs}

The TEM of two kinds of CNC are shown in Fig. 1. It can be observed that the T-CNC was thin and short. The length $(L)$ and diameter $(D)$ of T-CNC was $150 \pm 50 \mathrm{~nm}$, and $30 \pm 10 \mathrm{~nm}$, respectively, and the aspect ratio $(L / D)$ was 5 to 10 . The $\mathrm{S}-\mathrm{CNC}$ had the characteristics of coarse and long, with an $L$ value of $250 \pm 50 \mathrm{~nm}$, a $D$ value of $50 \pm 20$ $\mathrm{nm}$, and an $L / D$ ratio of 4 to 10 . Both kinds of $C N C$ had a certain agglomeration, which was caused by poor stability of CNC suspension in solution.
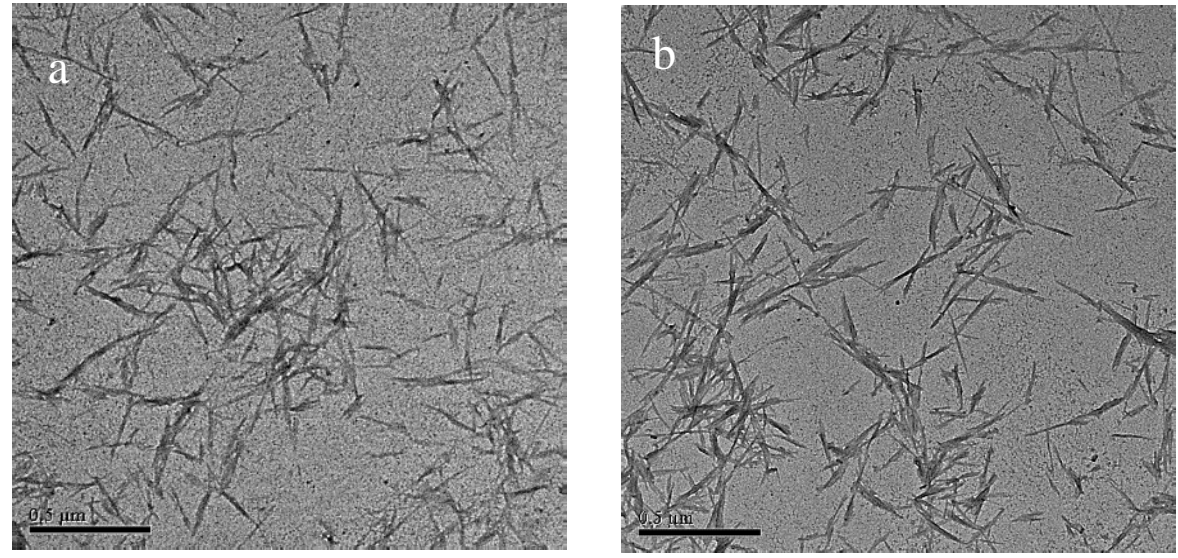

Fig. 1. TEM of T-CNC (a) and S-CNC (b)

\section{FTIR Spectral Analysis}

FTIR spectra of insulating paper containing different CNC are shown in Fig. 2.

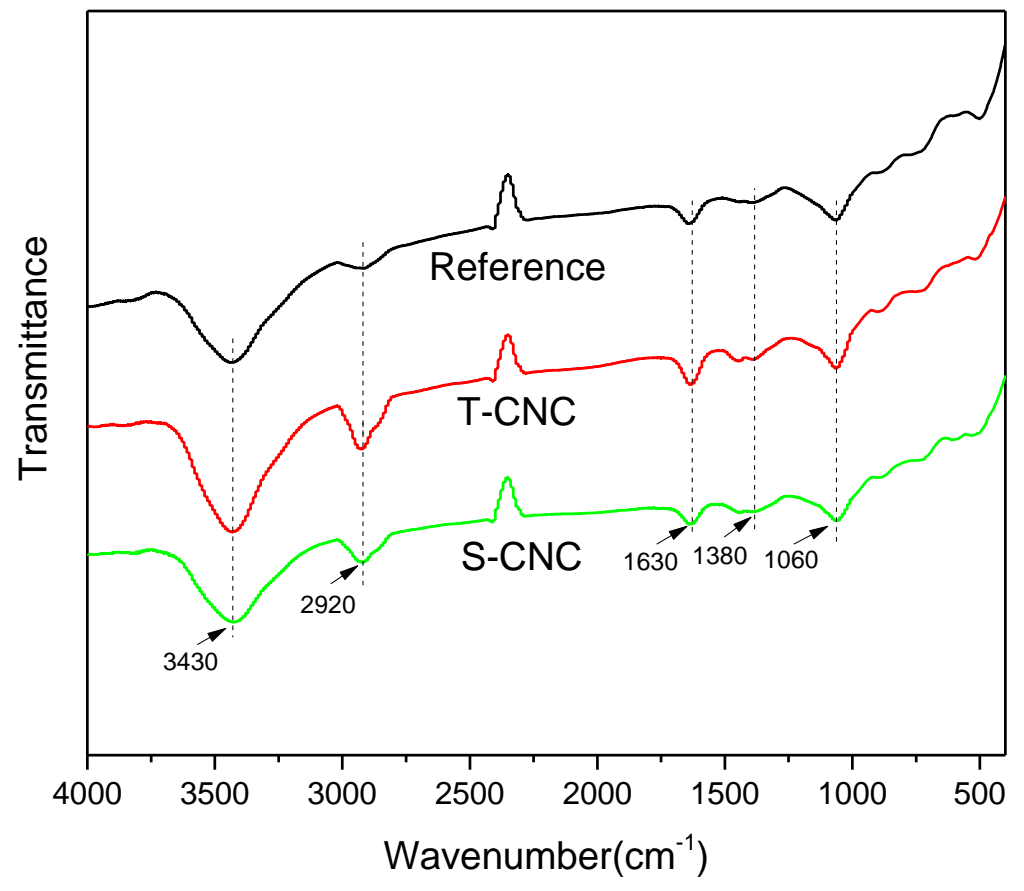

Fig. 2. FTIR spectra of reference insulating paper and insulating paper containing T-CNC and SCNC 
Similar functional groups were observed for the reference insulating paper, such as insulating paper containing T-CNC and S-CNC, which indicated that the CNC had a small effect on the chemical composition of the insulating paper. The bands at $3430 \mathrm{~cm}^{-1}$ and $1380 \mathrm{~cm}^{-1}$ were attributed to the $\mathrm{O}-\mathrm{H}$ stretching vibration and a $\mathrm{C}-\mathrm{H}$ bending vibration of the intermolecular hydrogen bond, respectively. It can be seen that the intensity of the absorption peak at $3430 \mathrm{~cm}^{-1}$ of the insulating paper containing T-CNC and S-CNC was much higher than that of the reference insulating paper, which indicated the presence of $\mathrm{CNC}$ in the modified insulating paper. The band at $2920 \mathrm{~cm}^{-1}$ was due to the asymmetric stretching of $-\mathrm{CH}_{2}$, and its density was relatively higher for the insulating paper containing T-CNC and S-CNC. The band at $1060 \mathrm{~cm}^{-1}$ was due to the stretching of C-O, and the bands at $1630 \mathrm{~cm}^{-1}$ could be owing to the stretching of conjugate $\mathrm{C}=\mathrm{O}$. For the insulating paper containing T-CNC, the intensity of absorption peak at $1630 \mathrm{~cm}^{-1}$ was higher, because the carbonyls of T-CNC were more than that of S-CNC.

\section{XRD Analysis}

The XRD patterns of reference insulating paper such as insulating paper containing T-CNC and S-CNC are presented in Fig. 3. Three kinds of insulating paper had four diffraction peaks at $2 \theta=15.2^{\circ}, 16.3^{\circ}, 22.6^{\circ}$, and $34.5^{\circ}$, and the positions of the peaks were basically the same, which belong to the crystal plane (110), (110), (002), and (040), respectively. The results showed that the crystal types of cellulose of insulating paper were all cellulose I. The crystallinity index $(C I)$ was calculated by the peak height method and the crystallinity index of the insulating paper containing T-CNC (CI 84.01\%) was higher than that of the reference insulating paper (CI 82.11\%), which can be attributed to the high crystallinity of T-CNC. However, the crystallinity index of the insulating paper containing S-CNC (CI 80.31\%) was lower than that of the reference insulating paper (CI 82.11\%), which may be caused by partial degradation of the crystallization area by acid hydrolysis (Bondeson et al. 2006; Pan et al. 2013).

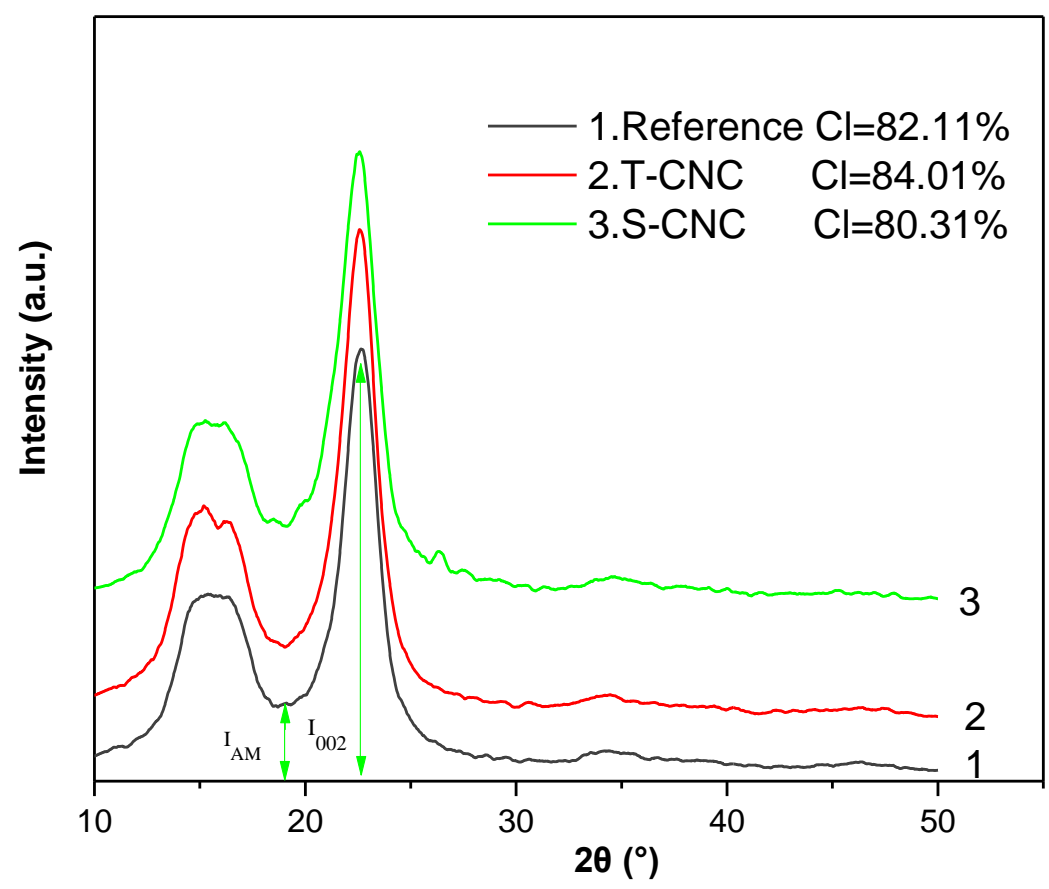

Fig. 3. XRD of reference insulating paper and insulating paper containing T-CNC and S-CNC 


\section{Effect of CNC on the Tensile Strength of Insulating Paper}

Tensile strength is a very important mechanical property of insulating paper. Figure 4 shows that the tensile index of insulating paper first increased and then decreased with the increase of CNC content. The tensile index reached the maximum value when the CNC dosage was $0.9 \%$, which is $70.22 \mathrm{~N} \cdot \mathrm{m} / \mathrm{g}$ for T-CNC, $21.70 \%$ higher than that of the reference insulating paper; $66.12 \mathrm{~N} \cdot \mathrm{m} / \mathrm{g}$ for $\mathrm{S}-\mathrm{CNC}, 14.57 \%$ higher than that of the reference insulating paper. The $\mathrm{H}$-bonding (from electrostatic and charge transfer) and superposition interactions (from van der Waals interactions and hydrophobicity) determined the biomolecular structure of the cellulose layer (Müller-Dethlefs and Hobza 2000). The improvement of the tensile index of insulating paper containing CNC can be attributed to the rich free hydroxyl groups on the surface of CNC. When the CNC was retained on the insulating paper, CNC would fill in the gaps within the paper to improve the paper strength. The network structure formed between the fibers and enhanced the adhesion between the fibers, which improved the tensile strength of paper. When the CNC dosage was higher than $0.9 \%$, the fibers began to aggregate, which reduced the tensile strength of the paper. Figure 3 also shows that T-CNC was noticeable better than S-CNC in enhancing the tensile strength of insulating paper.

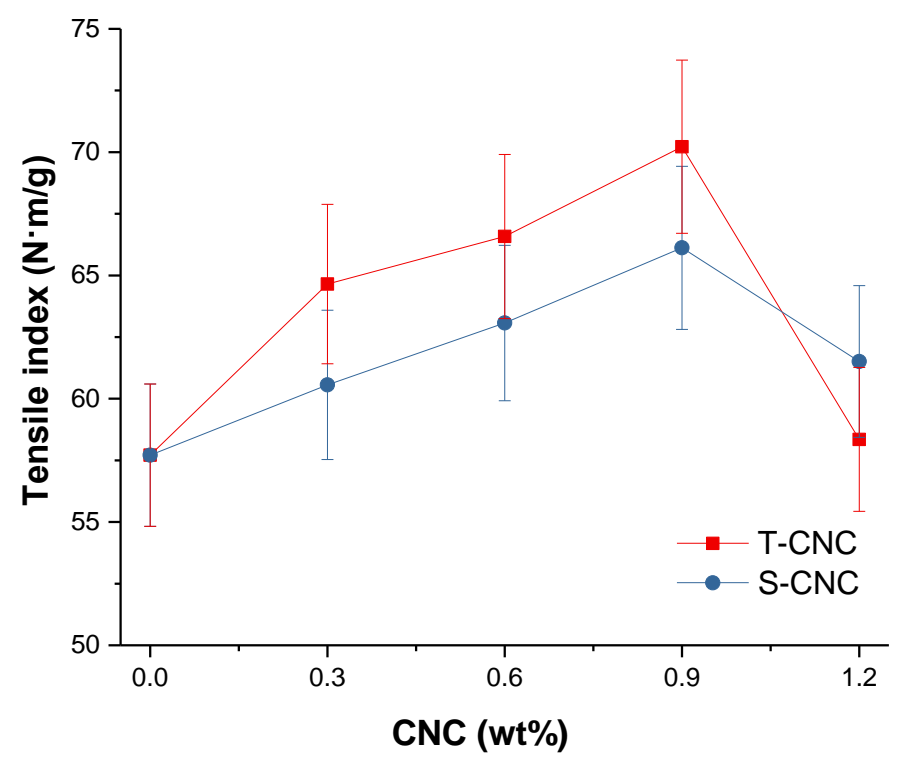

Fig. 4. Effect of $\mathrm{CNC}$ on the tensile strength of insulating paper

\section{Effect of CNC on the AC Breakdown Strength of Insulating Paper}

The AC breakdown strength is an important insulating characteristic of insulating paper. Figures 5 and 6 showed the effects of CNC on the AC breakdown strength of insulating paper in air and in oil. The AC breakdown strength of insulating paper in air increased gradually with the increase of the $\mathrm{CNC}$ dosage. When the $\mathrm{CNC}$ dosage was $0.9 \%$, the AC breakdown strength in air reached the maximum value, which was $7.38 \mathrm{kV} / \mathrm{mm}$ for T-CNC, $7.89 \%$ higher than that of the reference paper; and $7.31 \mathrm{kV} / \mathrm{mm}$ for S-CNC, which was $6.87 \%$ higher than that of the reference paper. The CNC was nano-particle sized and had many hydroxyl groups on its surface, which can be filled into the inner gaps of the insulating paper and form hydrogen bonds to adsorb tightly on the surface of the fiber. It can reduce the space charge accumulation and increase the density of the deep level trap in insulating paper, which results in an improvement in the insulating property of the 
insulating paper (Nam et al. 2014). The effect of T-CNC on the AC breakdown strength in air was slightly better than that of S-CNC.

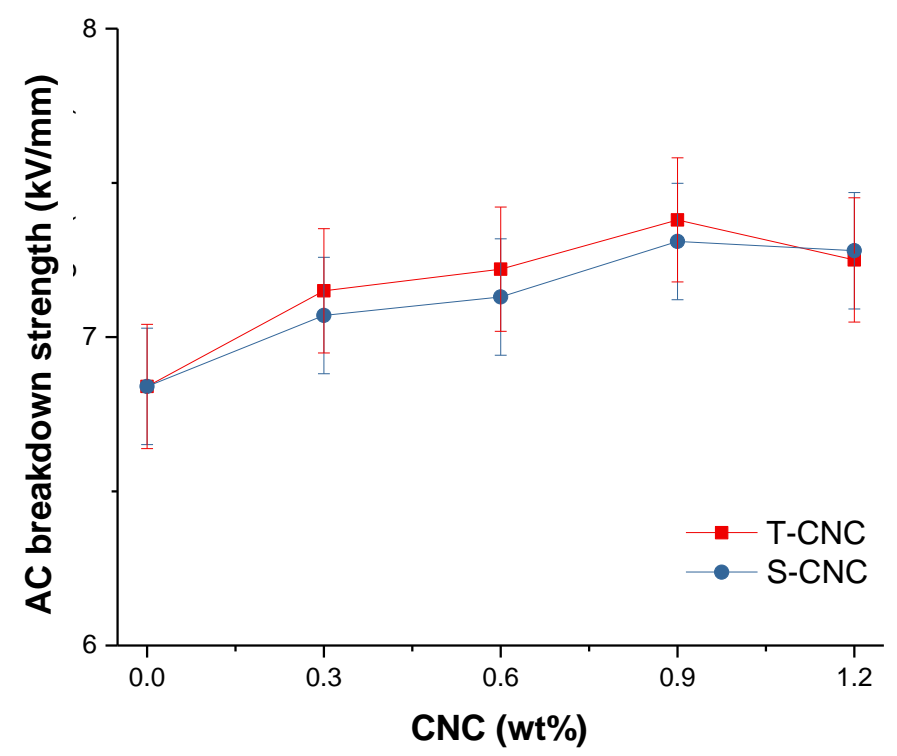

Fig. 5. Effect of $\mathrm{CNC}$ on the $\mathrm{AC}$ breakdown strength of insulating paper in air

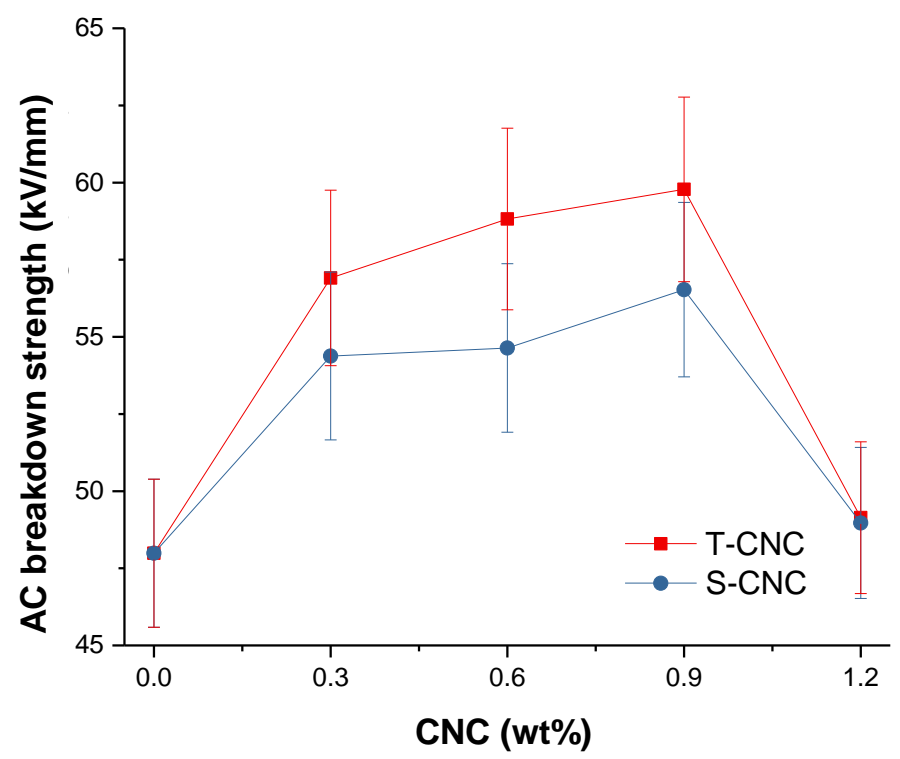

Fig. 6. Effect of $C N C$ on the $A C$ breakdown strength of insulating paper in oil

Oil-paper insulation is the main insulation method of transformer and the insulating strength of oil-paper is very important. Figure 6 shows that the AC breakdown strength of insulating paper in oil noticeably improved with the increase of the $\mathrm{CNC}$ dosage. When the $\mathrm{CNC}$ dosage was $0.9 \%$, the AC breakdown strength of T-CNC and S-CNC insulating paper in oil were $59.78 \mathrm{kV} / \mathrm{mm}$ and $56.53 \mathrm{kV} / \mathrm{mm}$, which were $24.6 \%$ and $17.8 \%$ higher than that of the reference insulating paper, respectively. This was because the addition of $\mathrm{CNC}$ has improved the oil absorption rate of insulating paper, which would be confirmed in the following discussion, thus improving the insulation strength of the oil-paper system. However, when the CNC dosage was more than $0.9 \%$, the AC breakdown strength of insulating paper in oil decreased rapidly. This was because the large amount of CNC would 
cause fiber to flocculate, which reduced the electrical strength. The results also showed that the effect of T-CNC on the AC breakdown strength in oil was slightly better than that of S-CNC. It was related to the source of T-CNC and S-CNC. Figures 4 and 5 also showed that the AC breakdown strength of insulating paper in oil was much higher than that in air, which also proved that oil-paper insulation in transformer was a good way of insulation.

\section{Effect of CNC on the Oil Absorption Rate of Insulating Paper}

Oil absorption rate is an important parameter of insulating paper that affects the stability of the oil-paper insulation system. In general, the dielectric coefficient of insulating paper is 4 to 5, while that of insulating oil is about 2.2. Under the action of the electric field, the field intensity shared in composite insulation is inversely proportional to the dielectric coefficient of the material (Wu et al. 2012). Improving the oil absorption rate of insulating paper is beneficial to the distribution of electric field intensity. Figure 7 shows the effect of CNC on the oil absorption rate of insulating paper. It can be seen that the oil absorption rate of insulating paper increased significantly with the increase of the CNC dosage. The oil absorption rate was the highest when the CNC dosage was $0.9 \%$, which was $53.08 \%$ for T-CNC (39.40\% higher than that of the reference insulating paper), and $46.27 \%$ for S-CNC (21.54\% higher than that of the reference insulating paper). This indicated that the addition of $\mathrm{CNC}$ had a positive impact on the performance of insulating paper. The $\mathrm{CNC}$ has similar properties with cellulose and more adsorption points. It can improve the oil absorption rate of insulating paper, thus improving the insulation properties of oiled paper. The results also showed that the improvement of the oil absorption rate of insulating paper by T-CNC was more obvious than that by S-CNC. It may be that T-CNC had more carboxyl groups, which promoted the absorption of oil.

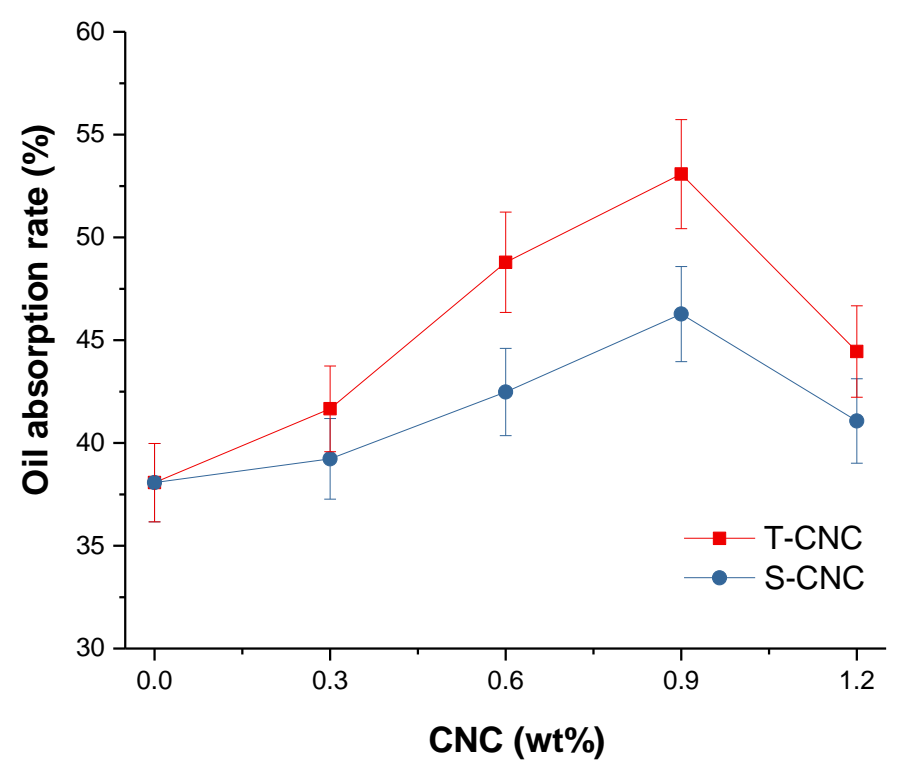

Fig. 7. Effect of CNC on the oil absorption rate of insulating paper

\section{Effect of CNC on the Conductivity of Insulating Paper Extract}

Conductivity of insulating paper extract is an important parameter of insulating paper, which has great influence on the insulating property of insulating paper. Figure 8 shows the effect of CNC on the conductivity of insulating paper. It can be seen that T-CNC and $\mathrm{S}-\mathrm{CNC}$ had little influence on the conductivity of insulating paper with the increase of 
the $\mathrm{CNC}$ dosage, indicating that $\mathrm{CNC}$ had good compatibility with softwood fibers, which would not bring new impurities to the system and would not change the conductivity of insulating paper.

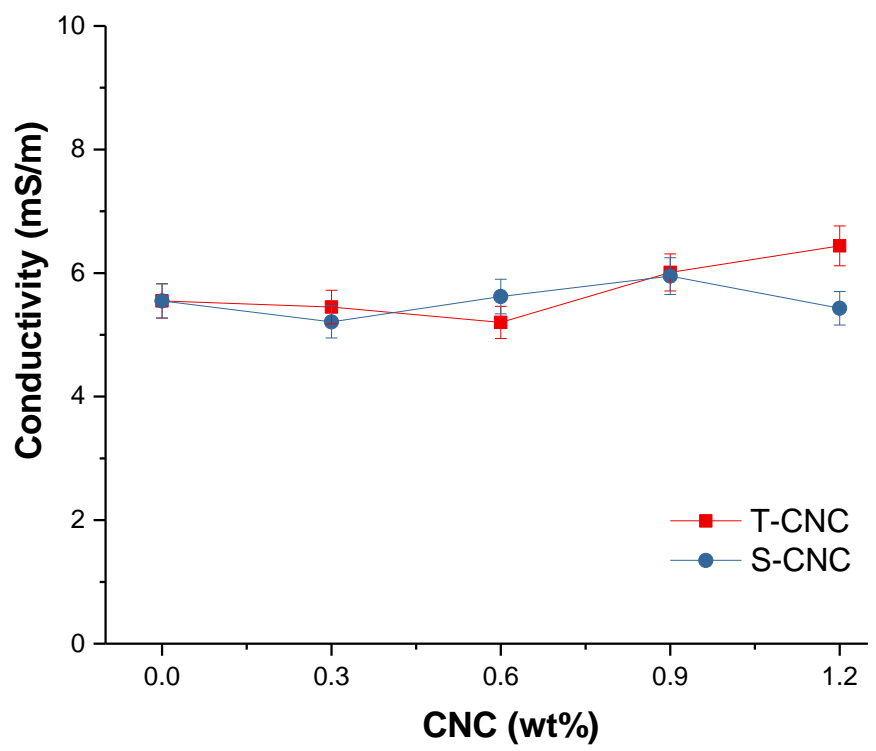

Fig. 8. Effect of CNC on the conductivity of insulating paper

\section{Effects of the Beating Degree on the Properties of Insulating Paper}

Beating degree is one of the important parameters of softwood pulp, which affects the length of fibers and the binding force between fibers, thus affecting the physical and electrical properties of insulating paper. Table 1 shows the effects of the different pulp beating degree on the properties of insulating paper containing T-CNC. With the increase of the beating degree, the tensile strength and the AC breakdown voltage in oil and air of the insulating paper all increased, but the oil absorption rate decreased gradually. When the beating degree of pulp was $37^{\circ} \mathrm{SR}$, the tensile strength of insulating paper increased by $2.46 \%$, the AC breakdown strength of insulating paper in oil and in air increased by $3.4 \%$ and $12.8 \%$, but the oil absorption rate decreased by $14.9 \%$, compared with the insulating paper of the beating degree $31^{\circ} \mathrm{SR}$. However, when the pulp beating degree increased from $37{ }^{\circ} \mathrm{SR}$ to $45^{\circ} \mathrm{SR}$, the variation range of the performance of insulating paper was very small.

Table 1. Effects of Beating Degree on the Properties of Insulating Paper Containing T-CNC

\begin{tabular}{|c|c|c|c|c|}
\hline $\begin{array}{c}\text { Beating Degree } \\
\left({ }^{\circ} \mathrm{SR}\right)\end{array}$ & $\begin{array}{c}\text { Tensile Index } \\
(\mathrm{N} \cdot \mathrm{m} / \mathrm{g})\end{array}$ & $\begin{array}{c}\text { AC Breakdown } \\
\text { Strength in Air } \\
(\mathrm{kV} / \mathrm{mm})\end{array}$ & $\begin{array}{c}\text { AC Breakdown } \\
\text { Strength in Oil } \\
(\mathrm{kV} / \mathrm{mm})\end{array}$ & $\begin{array}{c}\text { Oil Absorption } \\
\text { Rate }(\%)\end{array}$ \\
\hline 31 & $70.22 \pm 2.12$ & $7.38 \pm 0.25$ & $59.78 \pm 1.56$ & $53.08 \pm 1.27$ \\
\hline 37 & $71.95 \pm 2.18$ & $7.63 \pm 0.34$ & $67.41 \pm 1.84$ & $45.16 \pm 0.84$ \\
\hline 45 & $74.45 \pm 2.54$ & $7.90 \pm 0.41$ & $68.52 \pm 1.93$ & $44.01 \pm 0.76$ \\
\hline
\end{tabular}

Note: The data of each vertical column are significantly different $(\mathrm{P}<0.05)$.

A higher beating degree results in a higher degree of fiber fibrillation, and the closer bonding between the fibers improved the tensile strength of the insulating paper. Also, the high beating degree reduced the accumulation of space charge and increased the density of 
the depth well in the insulating paper, which improved the breakdown strength. With a closer fiber bonding, there is less space between the fibers. Considering the performance and energy consumption of insulating paper, when the T-CNC dosage was $0.9 \%$, the optimum beating degree of the softwood pulp was about $37{ }^{\circ} \mathrm{SR}$.

\section{SEM Analysis}

Figure 9 shows the SEM of reference insulating paper and insulating paper containing T-CNC. It can be seen that the surface of insulating paper containing T-CNC was smoother than that of the reference insulating paper. The introduced T-CNC can be adsorbed to fiber surfaces and acted as a nanofiller, which reduced the amount of space between the fibers and improve the smoothness of fiber surface. Thus it improved the properties of insulating paper.
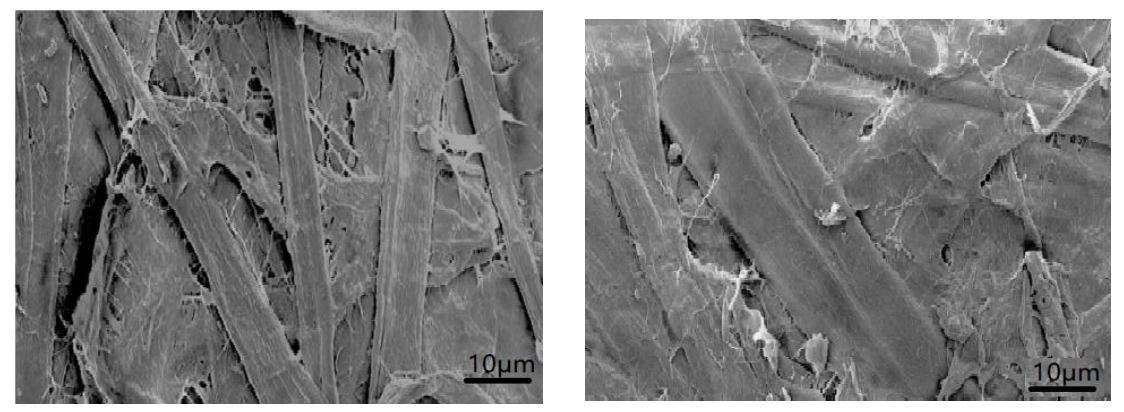

Fig. 9. SEM image of reference insulating paper (a) and Insulating Paper Containing T-CNC

\section{CONCLUSIONS}

1. The transformer insulating paper containing TEMPO-oxidized cellulose nanocrystals (T-CNC) and sulfuric acid hydrolyzed cellulose nanocrystals (S-CNC) were prepared and characterized. The intensity of the absorption peak at $3430 \mathrm{~cm}^{-1}$ of the insulating paper containing T-CNC and S-CNC was much higher than that of the reference insulating paper. The crystallinity index of the insulating paper containing T-CNC was higher than that of the reference insulating paper, but the crystallinity index of the insulating paper containing $\mathrm{S}-\mathrm{CNC}$ was lower than that of the reference insulating paper, due to the different preparation methods of $\mathrm{CNC}$.

2. The T-CNC and S-CNC both can effectively improve the mechanical and electrical performances of insulating paper, and the effects of T-CNC were a little better than that of S-CNC. When the T-CNC dosage was $0.9 \%$, the tensile strength was $70.22 \mathrm{~N} \cdot \mathrm{m} / \mathrm{g}$, which was $21.7 \%$ higher than the reference paper. Its AC breakdown strength in air, in oil and oil absorption rates of the insulating paper were $7.38 \mathrm{kV} / \mathrm{mm}, 59.78 \mathrm{kV} / \mathrm{mm}$, and $53.08 \%$ respectively, which was improved by $7.9 \%, 24.6 \%$, and $39.4 \%$, respective to that of the reference insulating paper. The T-CNC and S-CNC had little influence on the conductivity of insulating paper. The beating degree of pulp affect the mechanical and electrical properties of insulating paper containing $\mathrm{CNC}$. When the T-CNC dosage was $0.9 \%$, the optimum beating degree of softwood pulp was about $37{ }^{\circ} \mathrm{SR}$. SEM micrographs showed that the introduced $\mathrm{T}-\mathrm{CNC}$ can act as a nanofiller, improving the structure of insulating paper. 


\section{ACKNOWLEDGMENTS}

This work was financially supported by the National Natural Science Foundation of China (No. 31500495), Hunan Provincial Education Department Foundation of China (No. 18B150) and the Foundation of Key Laboratory of Pulp and Paper Science and Technology of Ministry of Education/Shandong Province of China (No. KF201801).

\section{REFERENCES CITED}

Bondeson, D., Mathew, A., and Oksman, K. (2006). "Optimization of the isolation of nanocrystals from microcrystalline cellulose by acid hydrolysis," Cellulose 13(2), 171-180. DOI: 10.1007/s10570-006-9061-4

Campano, C., Merayo, N., Balea, A., Tarrés, Q., Delgado-Aguilar, M., Mutjé, P., Negro, C., and Blanco, Á. (2017). "Mechanical and chemical dispersion of nanocelluloses to improve their reinforcing effect on recycled paper," Cellulose 25(1), 269-280. DOI: $10.1007 / \mathrm{s} 10570-017-1552-\mathrm{y}$

Cao, Z., Li, W. F., Liu, C., Peng, Y. Y., Huang, Y., and Xiao, Z. L. (2019).

"Development of potential embedded wireless sensor monitoring system based on low power bluetooth transmission," Chinese J. Anal. Chem. 47(2), 229-236. DOI: 10.19756/j.issn.0253-3820.181684

Ding, Q., Zeng, J., Wang, B., Gao, W., Chen, K., Yuan, Z., Xu, J., and Tang, D. (2018). "Effect of retention rate of fluorescent cellulose nanofibrils on paper properties and structure," Carbohydrate Polymers 186, 73-81. DOI: 10.1016/j.carbpol.2018.01.040

GB/T 7977 (2007). "Determination of electrical conductivity of water extracts from paper, board and pulp," Standardization Administration of China, Beijing, China.

Habibi, Y., Lucia, L. A., and Rojas, O. J. (2010). "Cellulose nanocrystals: Chemistry, self-assembly, and applications," Chemical Reviews 110(6), 3479-3500. DOI: $10.1021 /$ cr900339w

Herrera, M. A., Mathew, A. P., and Oksman, K. (2017). "Barrier and mechanical properties of plasticized and cross-linked nanocellulose coatings for paper packaging applications," Cellulose 24(9), 3969-3980. DOI: 10.1007/s10570-017-1405-8

Huang, J., Zhou, Y., Dong, L., Zhou, Z., and Zeng, X. (2017). "Enhancing insulating performances of presspaper by introduction of nanofibrillated cellulose," Energies 10(5), 681. DOI: 10.3390/en10050681

IEC 60243-3 (2001). "Electric strength of insulating materials-Test methods-Part 3: Addition requirements for 1.2/50 $\mu$ s impulse tests," International Electrotechnical Commission, Geneva, Switzerland.

IEC 60641-2 (2004). "Pressboard and presspaper for electrical purposcs-Part2: methods of tests," International Electrotechnical Commission, Geneva, Switzerland.

ISO 1924-1 (1992). "Paper and board- Determination of tensile properties-Part 1: Constant rate of loading method," International Organization for Standardization, Geneva, Switzerland.

ISO 5269-2 (2004). "Pulps- Preparation of laboratory sheets for physical testing- Part 2: Rapid-Köthen method," International Organization for Standardization, Geneva, Switzerland.

Liao, R., Zhang, F., Yuan, Y., Yang, L., Liu, T., and Tang, C. (2012). "Preparation and 
electrical properties of insulation paper composed of $\mathrm{SiO}_{2}$ hollow spheres," Energies 5(8), 2943-2951. DOI: 10.3390/en5082943

Liao, R., Lv, C., Yang, L., Zhang, Y., Wu, W., and Tang, C. (2013). “The insulation properties of oil-impregnated insulation paper reinforced with nano- $\mathrm{TiO}_{2}$," Journal of Nanomaterials 2013, 1-7. Article ID 373959. DOI: 10.1155/2013/373959

Lundgaard, L. E., Hansen, W., Linhjell, D., and Painter, T. J. (2004). "Aging of oilimpregnated paper in power transformers," IEEE Transactions on Power Delivery 19(1), 230-239. DOI: 10.1109/tpwrd.2003.820175

Martins, M. A., Teixeira, E. M., Corrêa, A. C., Ferreira, M., and Mattoso, L. H. C. (2011). "Extraction and characterization of cellulose whiskers from commercial cotton fibers," Journal of Materials Science 46(24), 7858-7864. DOI: 10.1007/s10853-011-5767-2

Müller-Dethlefs, K., and Hobza, P. (2000). "Noncovalent interactions: A challenge for experiment and theory," Chemical Reviews 100(1), 143-168. DOI: $10.1021 / \mathrm{cr} 9900331$

Nam, J. H., Jung, H. J., Yang, Y. S., Lee, T. H., Park, W. K., Kim, J. T., and Lee, J. H. (2014). "Space charge formations and electrical conductivities characteristics of nano composite XLPE," in: Proceedings of 2014 International Symposium on Electrical Insulating Materials, Niigata City, Japan, pp. 445-448. DOI: 10.1109/iseim.2014.6870814

Oommen, T. V., and Prevost, T. A. (2006). "Cellulose insulation in oil-filled power transformers: Part II maintaining insulation integrity and life," IEEE Electrical Insulation Magazine 22(2), 5-14. DOI: 10.1109/mei.2006.1618996

Pan, M., Zhou, X., and Chen, M. (2013). "Cellulose nanowhiskers isolation and properties from acid hydrolysis combined with high pressure homogenization," BioResources 8(1), 933-943. DOI: 10.15376/biores.8.1.933-943

Prevost, T. A., and Oommen, T. V. (2006). "Cellulose insulation in oil-filled power transformers: Part I- history and development," IEEE Electrical Insulation Magazine 22(1), 28-35. DOI:10.1109/mei.2006.1618969

Sheng, Y. Y., You, Y., Cao, Z., Liu, L., and Wu, H. C. (2018). "Rapid and selective DNA-based detection of melamine using $\alpha$-Hemolysin nanopore," Analyst 143(10), 2411-2415. DOI: 10.1039/c8an00580j

Tang, C., Zhang, S., Li, X., and Zhou, Q. (2016). "Molecular dynamics simulations of the effect of shape and size of $\mathrm{SiO}_{2}$ nanoparticle dopants on insulation paper cellulose," AIP Advances 6(12), 125106. DOI: 10.1063/1.4971280

Tang, C., Li, X., Li, Z., and Hao, J. (2017). "Interfacial hydrogen bonds and their influence mechanism on increasing the thermal stability of nano-SiO2-modified meta-aramid fibres," Polymers 9(10), 504. DOI: 10.3390/polym9100504

Tang, C., Zhang, S., Wang, X., and Hao, J. (2018). "Enhanced mechanical properties and thermal stability of cellulose insulation paper achieved by doping with melaminegraftednano-SiO 2 ," Cellulose 25(6), 3619-3633. DOI: 10.1007/s10570-018-1813-4

Wu, H., Li, C., Qi, B., Zhao, X., Lv, J., and Zhao, L. (2012). "The electric field distribution in oil-paper insulation under combined AC-DC voltage," in: 2012 IEEE International Conference on Condition Monitoring and Diagnosis, Bali, Indonesisa, pp. 1098-1101. DOI: 10.1109/cmd.2012.6416349

Yuan, Y., and Liao, R. (2014). "A novel nanomodified cellulose insulation paper for power transformer," Journal of Nanomaterials 2014, 1-6. Article ID 510864. DOI: $10.1155 / 2014 / 510864$ 
Zhang, S., Tang, C., Chen, G., Zhou, Q., Lv, C., and Li, X. (2015). "The influence and mechanism of nano $\mathrm{Al}_{2} \mathrm{O}_{3}$ to the thermal stability of cellulose insulation paper," Scientia Sinica Technologica 45(11), 1167-1179. DOI: 10.1360/N092015-00207

Ziomek, W. (2012). "Transformer electrical insulation [Editorial]," IEEE Transactions on Dielectrics and Electrical Insulation 19(6), 1841-1842. DOI: 10.1109/tdei.2012.6396938

Article submitted: March 7, 2019; Peer review completed: May 4, 2019; Revised version received: June 8, 2019; Accepted: June 15, 2019; Published: July 8, 2019.

DOI: $10.15376 /$ biores.14.3.6837-6850 